Article

\title{
Enhanced Oxidation Resistance of Polyphenylene Sulfide Composites Based on Montmorillonite Modified by Benzimidazolium Salt
}

\author{
Jian Xing ${ }^{1, *}$ (D), Zhenzhen $\mathrm{Xu}^{1}$ and Bingyao Deng ${ }^{2}$ \\ 1 School of Textile and Garment, Anhui Polytechnic University, Wuhu 241000, China; \\ xuzhenzhen@ahpu.edu.cn \\ 2 Key Laboratory of Science \&Technology of Eco-Textile, Ministry of Education, Jiangnan University, \\ Wuxi 214122, China; bydeng@jiangnan.edu.cn \\ * Correspondence: Xingjian@ahpu.edu.cn; Tel.: +86-158-6142-3618
}

Received: 2 December 2017; Accepted: 13 January 2018; Published: 17 January 2018

\begin{abstract}
Organic montmorillonite (MMT) modified by 1,3-dihexadecyl-3H-benzimidazolium bromide (Bz) was used to prepare polyphenylene sulfide (PPS)/MMT composites by melting intercalation. The PPS/MMT composites showed mixed morphology, being comprised of exfoliated and intercalated structures with slight agglomerates. The tensile property of PPS/MMT composites was significantly improved due to the good dispersion of the MMT nanolayers. The test results showed that the tensile strength retention of PPS/MMT composites was higher than that of pure PPS after the oxidation treatment. Moreover, FTIR and XPS analyses were also used to evaluate the oxidation resistance of PPS composites. The FTIR analysis confirmed that adding MMT could better limit the damage of the $\mathrm{C}-\mathrm{S}$ group and retard the generation of sulfuryl groups $\left(-\mathrm{SO}_{2}-\right)$ during the oxidation treatment compared to pure PPS. The XPS analysis also suggested that the addition of MMT could reduce the chemical combination of the elements sulfur $(\mathrm{S})$ and oxygen $(\mathrm{O})$ during oxidation treatment. Furthermore, the MMT nanolayers could also promote the transfer of $\mathrm{S}$ from a $\mathrm{C}-\mathrm{S}$ bond into an $-\mathrm{SO}_{2}-$ group.
\end{abstract}

Keywords: polyphenylene sulfide; organic montmorillonite; oxidation resistance; tensile properties; thermal stability

\section{Introduction}

Polyphenylene sulfide (PPS) is an attractive high-performance thermoplastic polymer which possesses high thermal stability, good mechanical properties and excellent fire resistance [1-4]. Due to its outstanding performance, PPS has been widely applied in the field of high temperature filtration $[5,6]$. However, PPS can be easily oxidized and crosslinked due to the low bond energy of the C-S-C bond. Therefore, research about improving the oxidation resistance of PPS has been reported over the last few decades [7-9]. Thus far, the methods of antioxidant modification can be mainly divided into two categories: (1) the surface coating method and (2) the direct addition of nanoparticles or antioxidants $[6,8-13]$.

The direct addition of nanoparticles or antioxidants is commonly used to improve the oxidation resistance of PPS. Various nanoparticles such as silicon carbide $(\mathrm{SiC})$, silicon dioxide $\left(\mathrm{SiO}_{2}\right)$, montmorillonite (MMT), carbon black, etc. $[11,13,14]$, have been directly added into PPS resin to improve the oxidation resistance. Sugama [9] used octadecylamine as a pretreatment agent to modify montmorillonite (MMT). The obtained organic MMT was then added to the PPS slurry coating. The results showed that the addition of MMT could retard the hydrothermal oxidation of PPS coatings. Zhang et al. [4] blended $\mathrm{TiO}_{2}$ and benzotriazole with PPS via melt compounding to prepare a PPS-based 
melt spun fiber. The tests showed that the addition of $\mathrm{TiO}_{2}$ and benzotriazole could significantly improve the light resistance of PPS fibers. The modified PPS melt spun fibers showed a weak color change after UV irradiation. Moreover, different kinds of antioxidants are also added into PPS resin by melt blending. Sugama [10] added three different antioxidants into PPS slurry coating, and this indicated that tetrakis [methylene (3,5-di-t-butyl-4-hydroxyhydrocinnamate)] methane (TMBHM) was most effective in hindering the hydrothermal oxidation of PPS coatings. In contrast with adding nanoparticles, the addition of antioxidants may create a wide range of problems, such as poor thermal stability of antioxidants, volatility of antioxidants during the melt processing, easy precipitation from the polymer matrix and low extraction resistance by the organic solvent.

The surface coating method can also be used to improve the oxidative stability of PPS fiber products $[15,16]$. The antioxidants or nanoparticles are made into a conditioning fluid, which can form a protective coating on the surface of PPS fiber products by the impregnation or spray method. However, there are a lot of defects which limit its potential application, such as the nonuniformity of film, easy peeling of protective film, and high production costs. In conclusion, the direct addition method is a simple and effective way to improve the oxidation resistance of PPS.

Among those nanofillers used in the direct addition method, the MMT nanolayers have attracted intensive attention due to their excellent oxygen barrier properties. This is because the MMT nanolayers can prevent oxygen infiltration and efficiently delay the thermal oxidation of the polymer [17-20]. Nevertheless, the poor dispersion of MMT nanolayers in the polymer matrix can significantly influence the properties and application of polymer/MMT composites. For PPS/MMT composites, the MMT nanolayers can only present good dispersion in the PPS slurry coating [9]. The MMT nanolayers only show an agglomeration morphology in PPS resin which can be directly used to prepare fibers and nonwoven fabrics due to the poor thermal stability of organic MMT [21]. However, only a good dispersion of MMT nanolayers can be effective in preventing the transfer of oxygen and heat. Therefore, achieving good dispersion of MMT nanolayers in PPS resin using a benzimidazolium surfactant was studied in this work. The influence of MMT nanolayers on the oxidation resistance of PPS resin was also investigated. Moreover, the antioxidative mechanism of the MMT nanolayers on PPS resin was also reported in this work.

\section{Experimental}

\subsection{Materials}

PPS resin (melt flow index of $150 \mathrm{~g} / 10 \mathrm{~min}$ at $315^{\circ} \mathrm{C} / \mathrm{kg}$ ) was obtained from Ruitai Technology Co., Ltd. (Suzhou, China). A commercial Na-MMT (CEC $=92 \mathrm{mmol} / 100 \mathrm{~g}$ ) was supplied by Fenghong Clay Co., Ltd. (Huzhou, China). Benzimidazole (98\%), 1-bromohexadecane (98\%), THF (99\%) and $\mathrm{NaOH}(96 \%)$ were purchased from Sinopharm Chemical Reagent Co., Ltd. (Shanghai, China).

\subsection{Preparation of Specimens}

1,3-dihexadecyl-3H-benzimidazolium bromide (Bz) was used as an organic modifier to modify Na-MMT to obtain organic MMT (Bz-MMT), which aimed to improve the dispersibility and compatibility of MMT nanolayers in PPS resin. The synthesis of Bz and the modification of MMT had also been performed in our previous work [22].

A SISZ-10A corotate twin-screw extruder (Ruiming Co., Ltd., Wuhan, China) was used to manufacture PPS/Bz-MMT composites containing different contents of Bz-MMT (0.5, 1, 3,5 and $10 \mathrm{wt} \%$ ) by melt compounding. The melt compounding was continued for $8 \mathrm{~min}$ at a screw speed of $30 \mathrm{rpm}$ at $290^{\circ} \mathrm{C}$. The PPS/Bz-MMT composites with various Bz-MMT contents were named as $\operatorname{PPSBM}_{x}$, where ${ }_{\mathrm{x}}$ is the content of Bz-MMT.

The specimens used for the tensile test were prepared by a SA-303 table-type test press machine (Tester Sanyo Co., Ltd., Osaka, Japan) and a SDL-100 sample cutting machine (Dumbbell Co., Ltd., Kobe, Japan). The PPSBM $x$ composites were hot pressed at $295{ }^{\circ} \mathrm{C}$ under $20 \mathrm{MPa}$ of pressure for $1 \mathrm{~min}$, 
and then cooled down to room temperature under $20 \mathrm{MPa}$. Next, the obtained films were incised to make the specimens used for the tensile test.

\subsection{Characterization of Material Properties}

The D-8 X-ray diffractometer (Bruker-axs Co., Ltd., Karlsruhe, Germany) with $\mathrm{Cu} \mathrm{K} \alpha$ radiation $(\lambda=0.154 \mathrm{~nm})$ at a generator voltage of $40 \mathrm{kV}$ and a current of $40 \mathrm{~mA}$ was used to analyze the diffraction behavior of MMT and PPSBM $x$ composites. Samples were pressed in stainless steel sample holders. All tests were conducted in the reflection mode at ambient temperature with $2 \theta$ varying between $1^{\circ}$ and $20^{\circ}$. The scanning speed was $1^{\circ} / \mathrm{min}$. The morphology and structure of $\mathrm{PPSBM}_{x}$ composites were also characterized using a transmission electron microscope (TEM) H-9500 (Hitachi. Co., Ltd., Tokyo, Japan) with an accelerating voltage of $120 \mathrm{kV}$.

The tensile properties of $\operatorname{PPSBM}_{x}$ composites were characterized by an EX-SX tensile tester (Tester Sangyo Co., Ltd., Osaka, Japan) with a $50 \mathrm{kN}$ load cell. The gauge length of specimens was $12 \mathrm{~mm}$, and the strain speed was $5 \mathrm{~mm} / \mathrm{min}$. The measurement of each sample was repeated at least 5 times. The thermal degradation behavior of $\operatorname{PPSBM}_{x}$ composites was analyzed using a Q-500 thermogravimetric analyzer (TA Instruments Co., Ltd., New Castle, DE, USA) in a nitrogen atmosphere with temperature from $30^{\circ} \mathrm{C}$ to $800{ }^{\circ} \mathrm{C}$ and with a heating rate of $10{ }^{\circ} \mathrm{C} / \mathrm{min}$.

The procedure of the oxidation resistance test was as follows. The specimens of PPSBM $x$ composites were soaked in a mixed acid $\mathrm{H}_{2} \mathrm{SO}_{4} / \mathrm{HNO}_{3} / \mathrm{HCl}(1: 1: 1)$ solution at $90{ }^{\circ} \mathrm{C}$ for $48 \mathrm{~h}$, which simulates the actual working environment of PPS resin [23]. After the acid exposure, the specimens were rinsed with distilled water five to seven times, and then the specimens were dried at room temperature. Lastly, the specimens were kept in a vacuum drying chamber for $24 \mathrm{~h}$ before the measurements were taken. The chemical group change of PPS was detected using the ATR-FTIR (Thermo Fisher Scientific Co., Ltd., Waltham, MA, USA). The test wave number range was from $4000 \mathrm{~cm}^{-1}$ to $400 \mathrm{~cm}^{-1}$. The elements analysis was performed using an AXIS-ULTRDLD multifunctional X-ray photoelectron spectrometer (XPS) (Shimadzu Co., Ltd., Kyoto, Japan).

\section{Results and Discussion}

\subsection{Morphology of PPSBM $M_{x}$ Composites}

The dispersion and intercalated structures of Bz-MMT nanolayers in PPS matrix were characterized using XRD and TEM. The XRD patterns of Na-MMT, Bz-MMT, and PPSBM $_{x}$ composites are shown in Figure 1. The interlayer spacing of Bz-MMT in $\operatorname{PPSBM}_{x}$ composites can be calculated using the Bragg equation based on the position of the diffraction peak. From Figure 1, it is shown that the diffraction peak of Na-MMT is $7.1^{\circ}$ while the diffraction peak of Bz-MMT significantly shifts to a smaller angle and the diffraction angle reduces to $2.7^{\circ}$. Moreover, it can also be observed that no new diffraction peak appears except the diffraction peak of the PPS matrix when the content of Bz-MMT is less than $1 \mathrm{wt} \%$ for $\operatorname{PPSBM}_{x}$ composites. However, when the load of Bz-MMT is more than $3 \mathrm{wt} \%$, the appearance of two new diffraction peaks at $2 \theta=3.0^{\circ}$ and $5.7^{\circ}$ can be evidently observed from Figure $1 \mathrm{~b}$. The new peaks are different from the diffraction peaks of Bz-MMT $\left(2 \theta=2.7^{\circ}\right.$ and $\left.5.4^{\circ}\right)$, but also the interlayer spacing is much larger than that of Na-MMT $(1.2 \mathrm{~nm})$ [22]. This phenomenon can be explained by the thermal degradation of Bz during the melt blinding and intercalation of PPS molecular chains. Therefore, from the XRD patterns, it can be calculated that the $\operatorname{PPSBM}_{x}$ composites exhibit an exfoliated morphology when the content of Bz-MMT is low. However, the absence of the diffraction peaks in $\operatorname{PPSBM}_{x}$ composites can also be attributed to low amounts of Bz-MMT, which are not easy to detect. The $\operatorname{PPSBM}_{x}$ composites possess a mixed morphology of exfoliated and intercalated structures when the content of Bz-MMT is high. Therefore, the dispersion of Bz-MMT nanolayers in PPS resin cannot be estimated based only on the XRD patterns. 

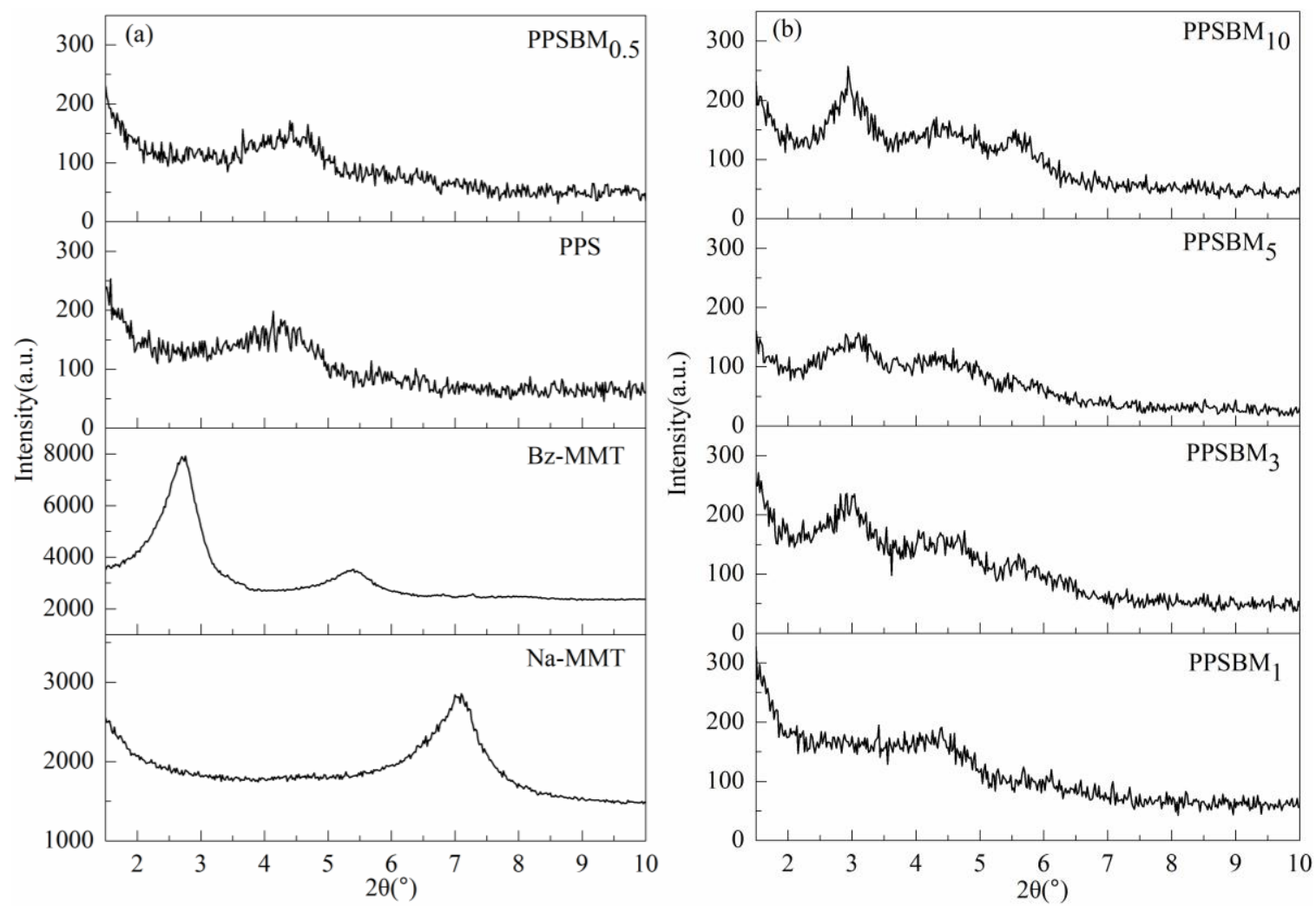

Figure 1. XRD patterns of pure polyphenylene sulfide (PPS) and $\operatorname{PPSBM}_{x}$ composites: (a) Na-MMT, Bz-MMT, PPS and PPSBM $0.5 ;$ (b) PPSBM 1, PPSBM $_{3}$, PPSBM $_{5}$ and PPSBM 10 .

To determine the details of the Bz-MMT dispersion in the PPS matrix, the morphology of composites was also measured using TEM. Figure 2 shows the TEM photomicrographs of PPSBM $_{x}$ composites, which can be used to evaluate the previous analysis of XRD patterns. It is evident that Bz-MMT distributes well in the PPS matrix but still forms some agglomerates. From Figure 2a,d, it is evident that there are individual and intercalated nanolayers in the PPS matrix, as well as a few agglomerates. The individual and intercalated nanolayers are also observed in Figure $2 b, e$ and c,f, but the agglomerates of Bz-MMT nanolayers increase in number and size as the Bz-MMT content increases. Therefore, the observed dispersion of Bz-MMT from the TEM images is not consistent with the analysis of XRD patterns. Meanwhile, in comparison with our previous work, the Bz can improve the compatibility of Na-MMT and the PPS matrix. The particles of Bz-MMT can disperse, intercalate, and exfoliate under the shear stress during the melt blending process. Therefore, the $\operatorname{PPSBM}_{x}$ composites exhibit a mixed morphology of exfoliated and intercalated morphology, but the agglomerates of Bz-MMT nanolayers cannot be avoided during the melt blending. 


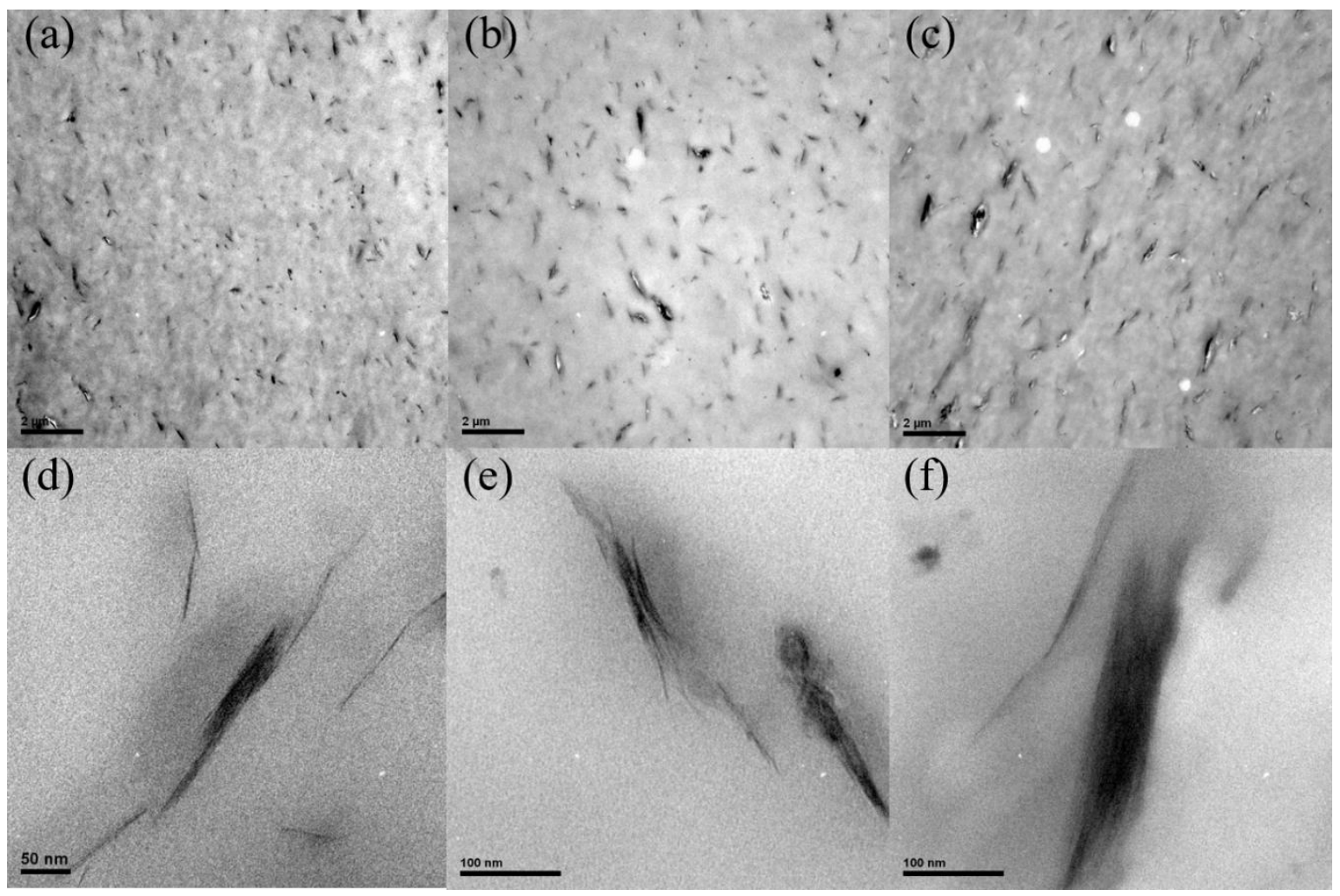

Figure 2. TEM images of $\operatorname{PPSBM}_{x}$ composites: (a,d) $1 \mathrm{wt} \%$, (b,e) $3 \mathrm{wt} \%$, and (c,f) $5 \mathrm{wt} \%$.

\subsection{Tensile Properties of PPSBM Composites}

The tensile properties of pure PPS and $\operatorname{PPSBM}_{x}$ composites are shown in Figure 3. It can be clearly observed that the tensile strength and tensile modulus of PPS resin significantly improves due to the addition of Bz-MMT. When the content of Bz-MMT is just $0.5 \mathrm{wt} \%$, the tensile strength and tensile modulus increase from 76.5 MPa and 1775.8 $\mathrm{MPa}$ to $123.8 \mathrm{MPa}$ and $2607.3 \mathrm{MPa}$, respectively. However, the tensile properties of $\operatorname{PPSBM}_{x}$ composites decrease with increasing the Bz-MMT contents. When the content of Bz-MMT is up to $10 \mathrm{wt} \%$, the tensile strength and tensile modulus are even lower than that of pure PPS. When a small amount of Bz-MMT is added into PPS resin, the Bz-MMT nanolayers can be exfoliated and intercalated in composites with slight agglomerations. The individual nanolayers can enlarge the propagation path of cracks and absorb energy to increase the plastic deformation during tensile stretching. Moreover, the interactions between nanolayers and PPS matrix can also significantly improve the tensile properties. The structure defects caused by a slight agglomeration of Bz-MMT nanolayers can be negligible. Therefore, the tensile properties of composites are improved. Furthermore, the MMT nanolayers can also act as heterogeneous nucleation agent to promote the crystallization of PPS, which can improve the tensile properties of PPS. However, with the increase of Bz-MMT content, the proportion of the exfoliated nanolayers decreases, and the proportion of the intercalated or agglomerated nanolayers increases. Additionally, the large agglomerates in Bz-MMT nanolayers can also cause serious structural defects, and the degradation of organic modifiers during melt blending can also induce the degradation of PPS macromolecular chains and cause the formation of structure defects in composites. Thus, the composites with a high content of Bz-MMT have a low tensile property. 


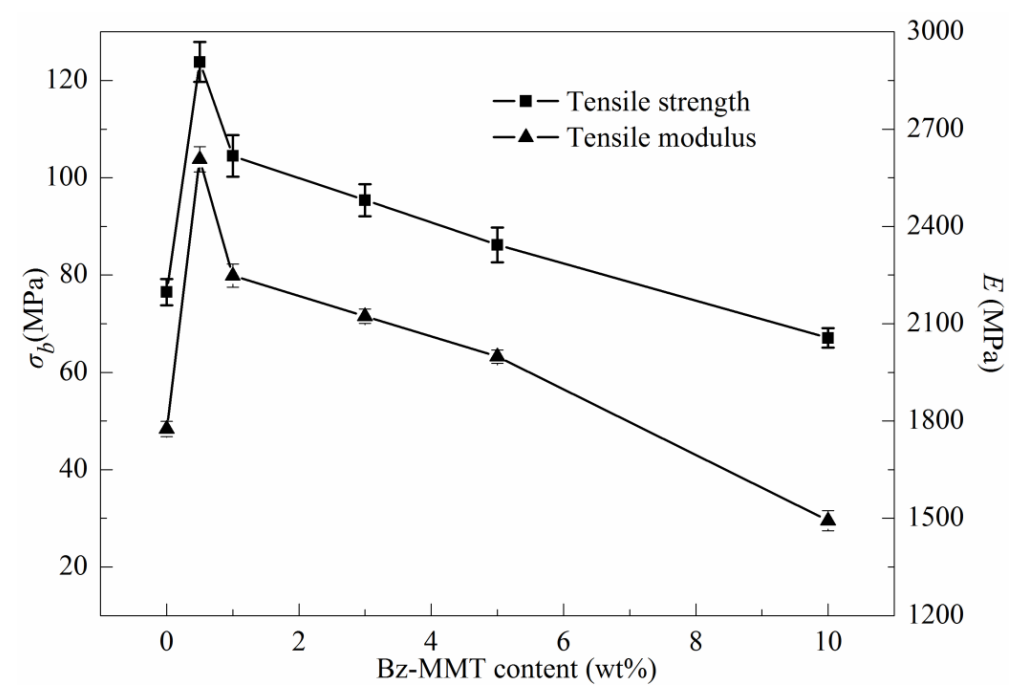

Figure 3. Tensile properties of PPS and $\operatorname{PPSBM}_{x}$ composites: $\left(\sigma_{b}\right)$ tensile strength; $(E)$ tensile modulus.

\subsection{Thermal Degradation of PPSBM ${ }_{x}$ Composites}

The TGA and derivative thermogravimetric analysis (DTG) curves of PPS and PPSBM $x$ composites are plotted in Figure 4. Moreover, the degradation temperatures at different percentages of weight loss $\left(T_{5 \%}, T_{15 \%}, T_{30 \%}\right.$, and $\left.T_{50 \%}\right)$ and the maximum decomposition rate $\left(T_{\max }\right)$ are also listed in Table 1.

Table 1. TGA parameters of PPS and $\operatorname{PPSBM}_{x}$ composites.

\begin{tabular}{ccccccc}
\hline Samples & $\boldsymbol{T}_{\mathbf{5 \%}}\left({ }^{\circ} \mathbf{C}\right)$ & $\boldsymbol{T}_{\mathbf{1 5 \%}}\left({ }^{\circ} \mathbf{C}\right)$ & $\boldsymbol{T}_{\mathbf{3 0} \%}\left({ }^{\circ} \mathbf{C}\right)$ & $\boldsymbol{T}_{\mathbf{5 0} \%}\left({ }^{\circ} \mathbf{C}\right)$ & $\boldsymbol{T}_{\boldsymbol{H R I}}\left({ }^{\circ} \mathrm{C}\right)$ & $\boldsymbol{T}_{\mathbf{m a x}}\left({ }^{\circ} \mathbf{C}\right)$ \\
\hline PPS $^{452.2}$ & 484.7 & 507.0 & 533.9 & 237.7 & 512.3 \\
PPSBM $_{0.5}$ & 484.5 & 508.9 & 528.1 & 554.4 & 250.2 & 536.5 \\
PPSBM $_{1}$ & 482.9 & 507.1 & 533.5 & 570.1 & 251.5 & 537.8 \\
PPSBM $_{3}$ & 470.9 & 501.1 & 524.8 & 553.6 & 246.6 & 536.6 \\
PPSBM $_{5}$ & 463.5 & 498.7 & 522.6 & 550.6 & 244.5 & 532.5 \\
PPSBM $_{10}$ & 450.6 & 492.1 & 518.4 & 549.1 & 240.7 & 532.1 \\
\hline
\end{tabular}

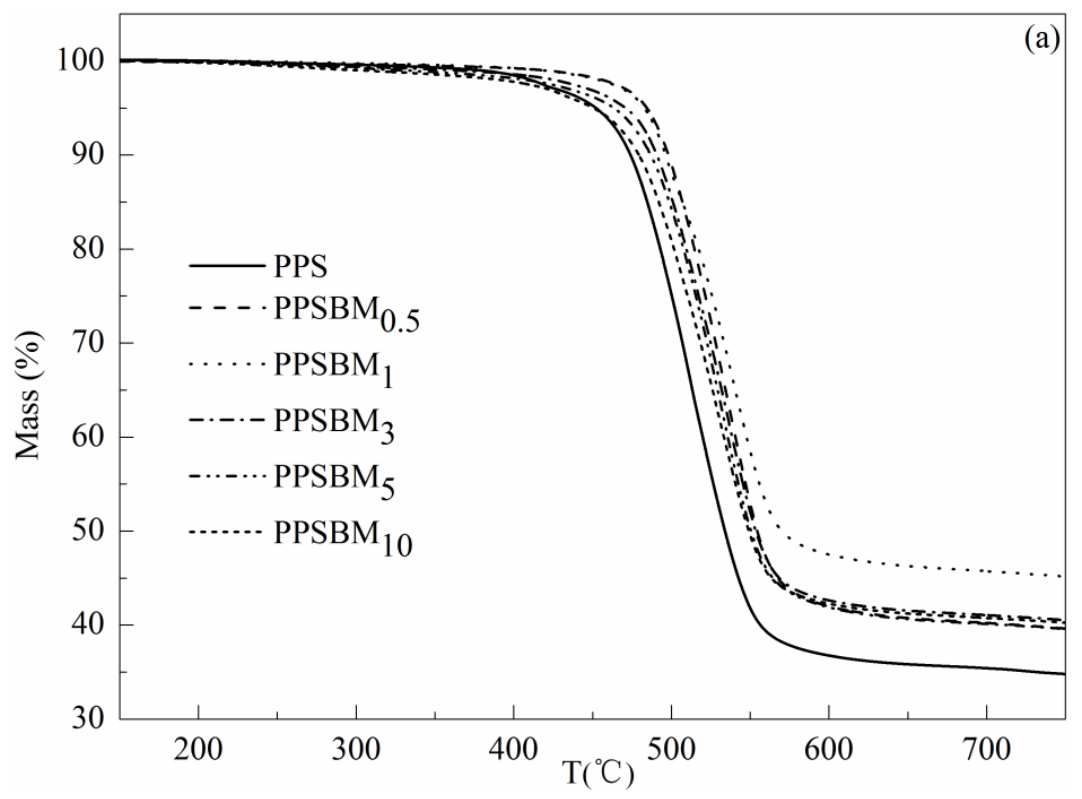

Figure 4. Cont. 


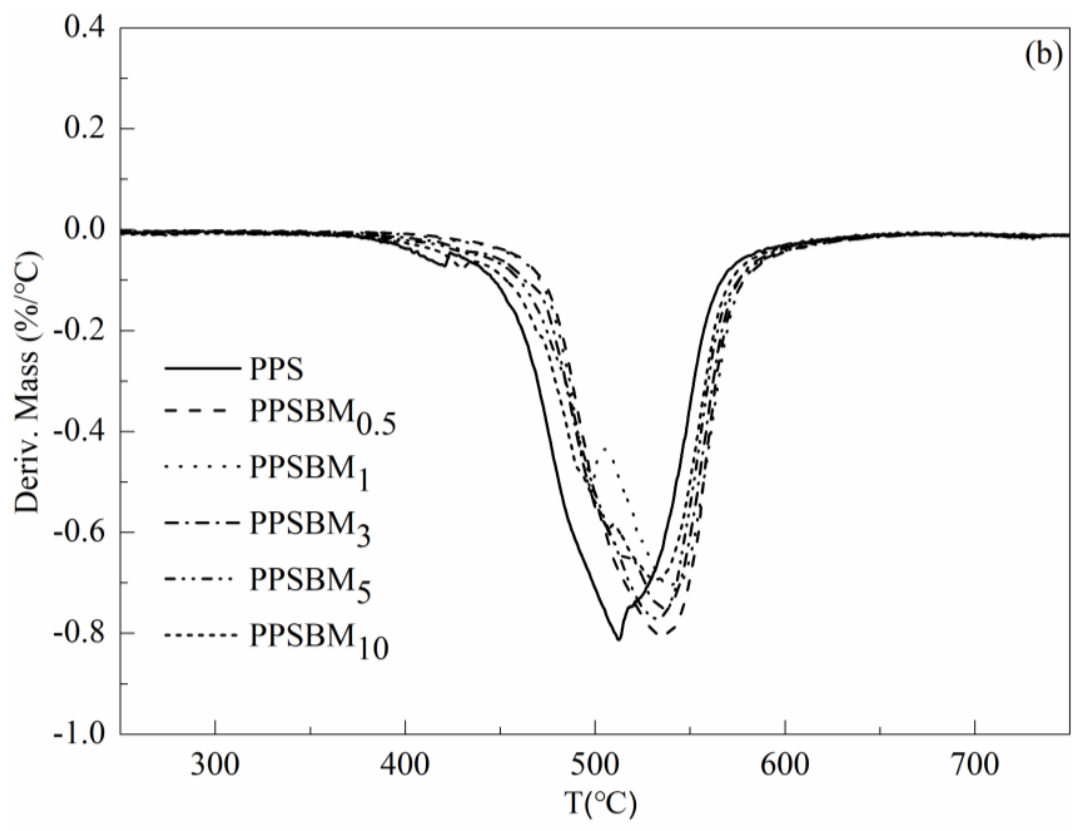

Figure 4. TGA (a) and DTG (b) curves of PPS and PPSBM $x$ composites.

From Figure 4, it can be clearly observed that both pure PPS resin and $\operatorname{PPSBM}_{x}$ composites exhibit a single stage thermal degradation with a large peak in DTG curves over the whole test temperature range. Furthermore, it is evident that the thermal stability of $\operatorname{PPSBM}_{x}$ composites show a significant improvement compared with that of pure PPS resin due to the addition of Bz-MMT. From Table 1, it can be found that the $T_{5 \%}$ of $\operatorname{PPSBM}_{x}$ composites is much higher than pure PPS resin when the Bz-MMT content is less than 5 wt \%. The $T_{5 \%}$ of $\operatorname{PPSBM}_{0.5}$ is $484.5^{\circ} \mathrm{C}$, which is $32.3^{\circ} \mathrm{C}$ higher than that of pure PPS. However, adding excessive Bz-MMT can also reduce the thermal stability of PPS due to the thermal degradation of the organic modifier at lower temperatures. The $T_{5 \%}$ of $\operatorname{PPSBM}_{10}$ is $1.6{ }^{\circ} \mathrm{C}$ lower than that of pure PPS resin. The temperature corresponding to the $T_{\max }$ firstly increases but then decreases with the increase of Bz-MMT content. The enhancement in thermal stability of PPS composites can be attributed to the mass transport barrier effect of Bz-MMT nanolayers, which can restrict the diffusion of gaseous decomposition products and slow the heat transfer during degradation [24]. Moreover, the Bz-MMT nanolayers can also promote the PPS matrix to form protective carbon piles during the degradation process, which can delay or even stop the transfer of heat and gaseous decomposition products [25-27].

The heat-resistant index $\left(T_{H R I}\right)$ is also used to represent the thermal stability of polymers, and can express the temperature which limits the long-time use [28,29]. The $T_{H R I}$ can be calculated by the following equation:

$$
T_{H R I}=0.49 \times\left[T_{5 \%}+0.6 \times\left(T_{30 \%}-T_{5 \%}\right)\right]
$$

where $T_{5 \%}$ and $T_{30 \%}$ is the corresponding degradation temperature of $5 \%$ and $30 \%$ weight loss, respectively. As shown in Table 1, the $T_{H R I}$ of composites also initially increases and then decreases with increasing additions of Bz-MMT. The $T_{H R I}$ of $\mathrm{PPSBM}_{1}$ is $13.8^{\circ} \mathrm{C}$ higher than that of pure PPS. This can be explained by the mass transport barrier effect and favorable dispersion of Bz-MMT. However, adding a high content of Bz-MMT can agglomerate in the matrix and damage the overall structure of composites. Therefore, the thermal stability of $\operatorname{PPSBM}_{x}$ composites decreases when the content of Bz-MMT is high. 


\subsection{Oxidation Resistance of PPSBM Composites}

Under the conditions of high temperature or a strongly acidic environment, polymer molecular chains are susceptible to oxygen, which can attack and cause the rupture of macromolecular chains. Moreover, free radicals can be generated when the oxidative cleavage of chains take place. The chain reaction of free radicals can also further aggravate the oxidation degradation of polymer molecular chains, which will exacerbate the destruction of material structure, damage the polymer's mechanical properties, and shorten the service life of the polymer.

At present, the methods of measuring the oxidation resistance of a polymer are varied. In this work, the changes of tensile properties, the type and content of functional groups, the element content and the valence state of the PPS composites are all used to characterize the oxidation resistance. This, in turn, can be used to explore the antioxidative mechanism of the Bz-MMT nanolayers on PPS resin.

\subsubsection{Tensile Strength Analysis}

Figure 5 shows the tensile strength changes of PPS and PPSBM $x$ composites after oxidation treatment. It is found that the tensile strength of pure PPS resin reduced from 76.5 MPa to 7.4 MPa. The tensile strength loss ratio is as high as $90.3 \%$. This indicates that the specimens are heavily oxidized by strong acid and high heat in the atmosphere of oxygen, which induces the oxidative cleavage of PPS molecular chains and a sharp decrease of tensile strength. In contrast, the tensile strength of PPSBM 0.5 resin is reduced from 104.5 $\mathrm{MPa}$ to $47.6 \mathrm{MPa}$. The tensile strength loss ratio is only $54.3 \%$. Moreover, the tensile strength of $\mathrm{PPSBM}_{1}$ resin is reduced from 95.4 MPa to $38.7 \mathrm{MPa}$. The tensile strength loss ratio is $59.4 \%$. Therefore, the tensile strength loss ratios of $\operatorname{PPSBM}_{x}$ composites are much smaller than that of pure PPS resin, and the tensile strengths of $\operatorname{PPSBM}_{x}$ composites are also significantly higher than that of pure PPS resin. This phenomenon can be attributed to the good dispersion of the Bz-MMT nanolayers in PPS matrix, which can delay the diffusion of heat and $\mathrm{O}_{2}, \mathrm{NO}_{x}$ and $\mathrm{SO}_{x}$ in the PPS matrix due to the mass transport barrier effect. Moreover, the Bz-MMT nanolayers can also hinder the emission of oxidative degradation products in the PPS matrix. Furthermore, the Bz-MMT nanolayers can result in heterogeneous nucleation crystallization, which promote the crystallization and reduce the proportion of amorphous region of PPS matrix [22]. Therefore, the degradation number of PPS molecular chains decreases, and the oxidation resistance of $\operatorname{PPSBM}_{x}$ composites increases compared to pure PPS resin.

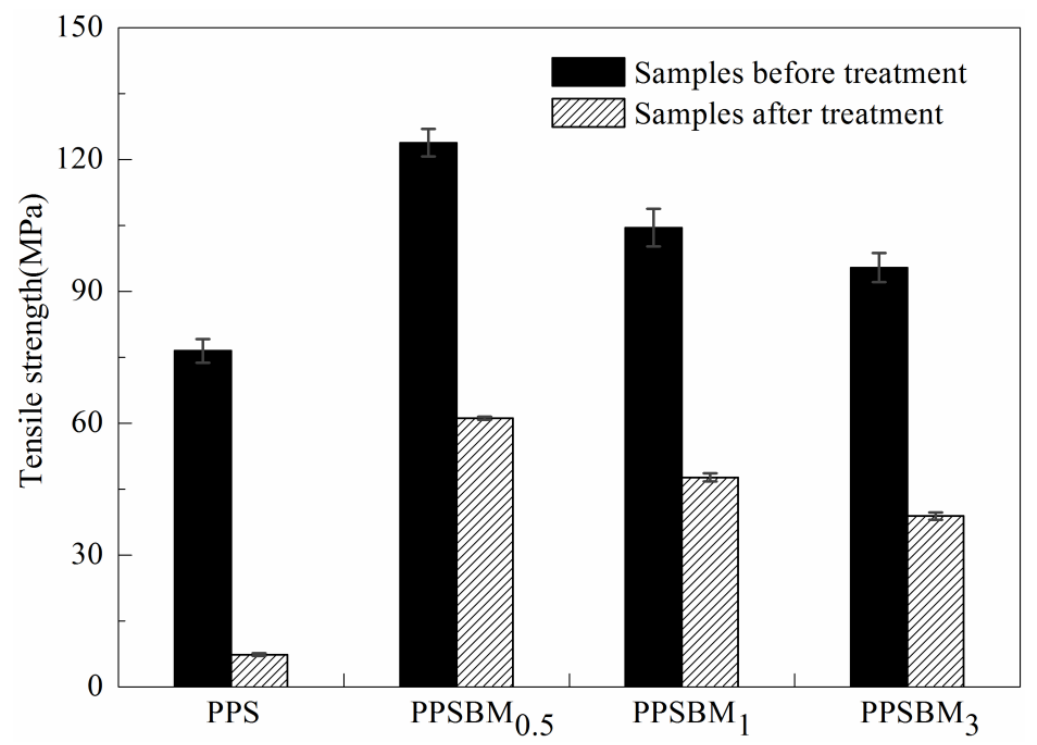

Figure 5. Tensile strength changes of PPS and $\operatorname{PPSBM}_{x}$ composites after oxidation treatment. 


\subsubsection{Chemical Functional Groups Analysis}

The changes in chemical functional groups are measured using ATR-FTIR, which can be used to characterize the oxidation resistance and analyze the antioxidative mechanism. The FTIR spectrum of pure PPS resin is shown in Figure 6.

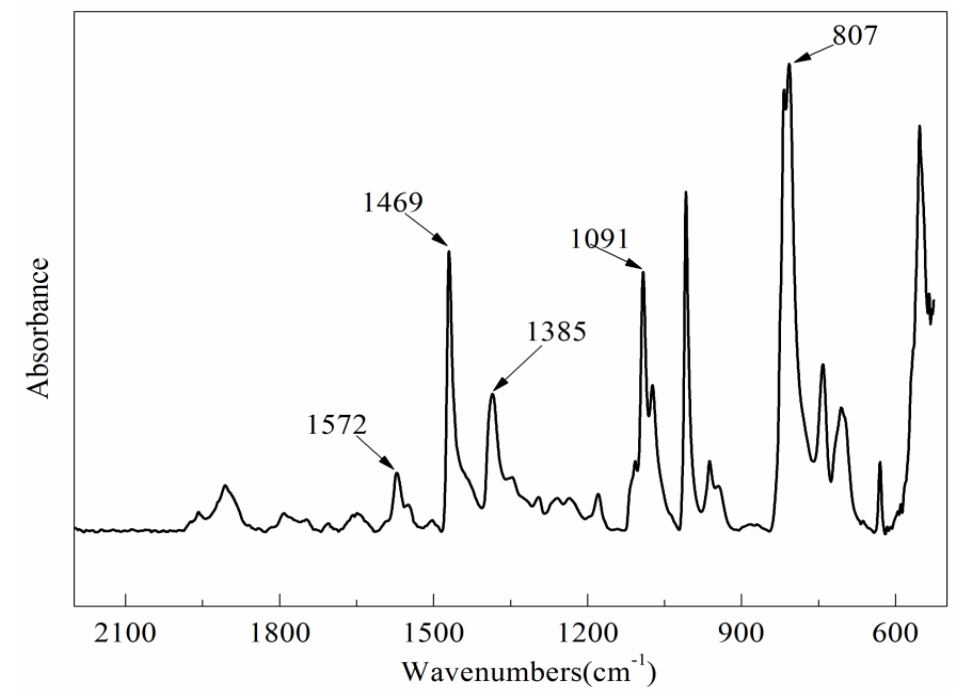

Figure 6. FTIR spectra of pure PPS resin.

It is found that $1572,1469,1385,1091$, and $807 \mathrm{~cm}^{-1}$ are the characteristic absorption peaks of pure PPS resin (Figure 6). The peaks at 1572, 1469, and $1385 \mathrm{~cm}^{-1}$ are attributed to the stretching vibration absorption of the benzene ring skeleton. The peak at $1091 \mathrm{~cm}^{-1}$ belongs to the stretching vibration absorption of the $\mathrm{C}-\mathrm{S}$ bond. The strong absorption peak at $807 \mathrm{~cm}^{-1}$ is the characteristic peak of the $\rho$-disubstituted benzene ring. Moreover, the peak at $1178 \mathrm{~cm}^{-1}$ is attributed to the stretching vibration absorption of $-\mathrm{SO}_{2-}$, and $1075 \mathrm{~cm}^{-1}$ is the stretching vibration absorption of -SO- [3]. The existence of $-\mathrm{SO}_{2}-$ and $-\mathrm{SO}$ - in pure PPS resin can be explained by the low bond energy of the C-S bond, which is easily oxidized during the synthesis, drying, and storage process of PPS resin. The peak at $1572 \mathrm{~cm}^{-1}$ also serves as a benchmark for comparison because it is the characteristic peak of PPS and cannot be attacked during oxidation treatment. Therefore, the relative absorbance of other absorption peaks can be obtained by comparison with its integral absorbance.

Figure 7 shows the FTIR spectra of PPS and PPSBM 1 composites after the oxidation treatment. The relative absorbance of different chemical groups is also listed in Table 2. It can be found that there is no apparent change in the chemical groups of PPS, but a new absorption peak at $1044 \mathrm{~cm}^{-1}$ which can be attributed to aryl ether appears. This indicates that the PPS chains are oxidized to promote cross-linking during oxidation treatment. The relative absorbance of $-\mathrm{SO}_{2}-$ at $1178 \mathrm{~cm}^{-1}$ has a significant increase, which indicates that the oxidation level of PPS resin intensifies. The relative absorbance of the $\mathrm{C}-\mathrm{S}$ bond at $1091 \mathrm{~cm}^{-1}$ dramatically reduces, and the relative absorbance of $-\mathrm{SO}-$ at $1091 \mathrm{~cm}^{-1}$ also decreases. The reduction of $-\mathrm{SO}-$ can be explained by the fact that the bond order of $\mathrm{S}=\mathrm{O}$ in $-\mathrm{SO}-$ is lower than that in $-\mathrm{SO}_{2-}$, which demonstrates that $-\mathrm{SO}$ - is more likely to be formed in PPS resin after the treatment. However, the $\mathrm{S}$ in -SO- has an unstable valence, and is easy to be oxidized again to form $-\mathrm{SO}_{2}-$ under the condition of oxidation. Moreover, the relative absorbance of the $\rho$-disubstituted benzene ring at $807 \mathrm{~cm}^{-1}$ is also lower than that of PPS before the treatment, which suggests that the oxidative cross-linking takes place in PPS resin. This phenomenon is also consistent with the generation of the aryl ether. In short, the degree of oxidation in pure PPS resin intensifies, and the oxidative cleavage and cross-linking take place in PPS molecular chains after the treatment. 

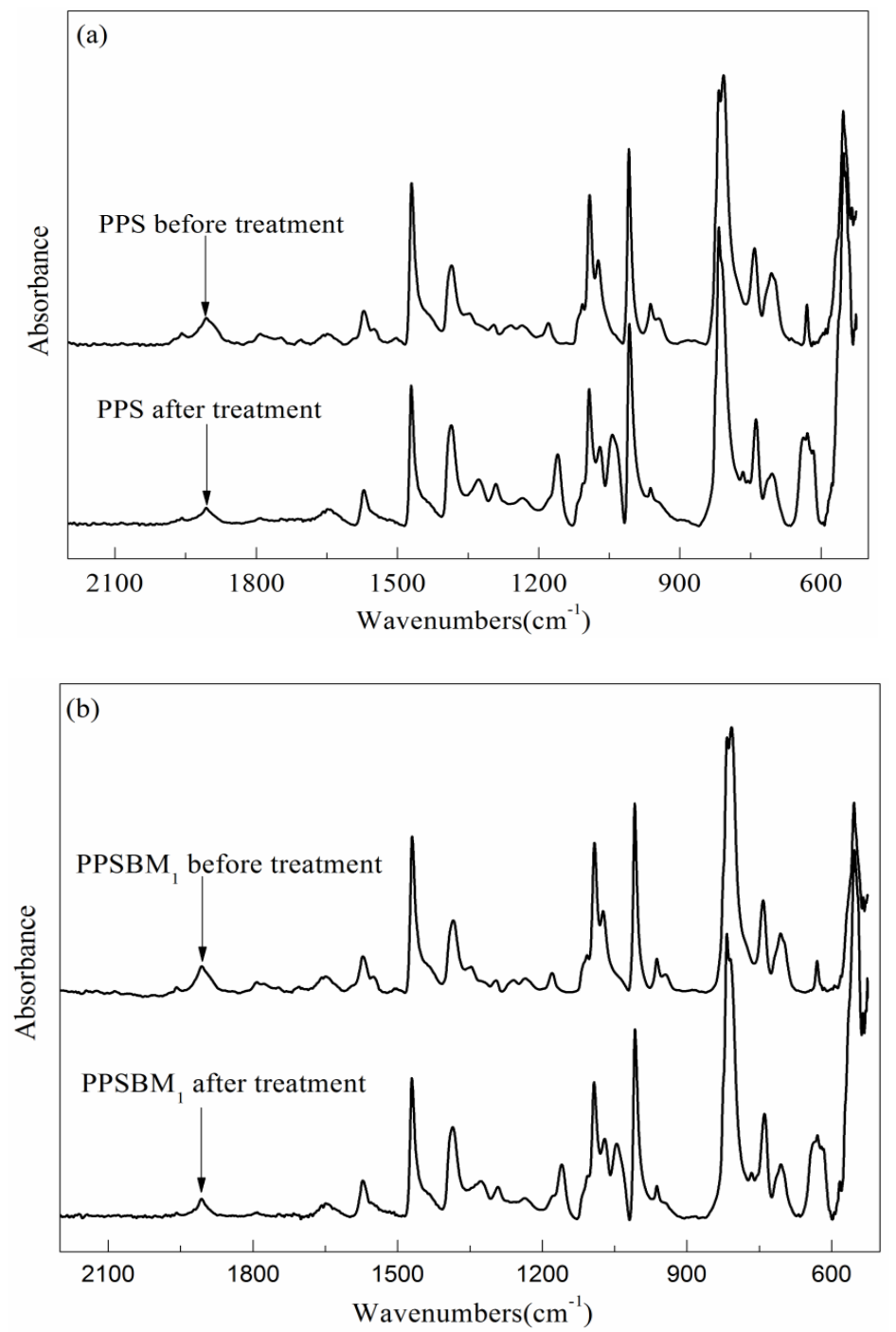

Figure 7. FTIR spectra of PPS (a) and PPSBM 1 composites (b) after the oxidation treatment.

Table 2. Relative absorbance of PPS and PPSBM 1 composites before and after the treatment.

\begin{tabular}{ccccc}
\hline \multirow{2}{*}{$\begin{array}{c}\text { Wavenumber } \\
\left(\mathbf{c m}^{-\mathbf{1}}\right)\end{array}$} & $\begin{array}{c}\text { PPS before } \\
\text { Treatment }\end{array}$ & $\begin{array}{c}\text { PPS after } \\
\text { Treatment }\end{array}$ & $\begin{array}{c}\text { PPSBM } \\
\text { Treatment }\end{array}$ & $\begin{array}{c}\text { PPSBM } \\
\text { Treative } \text { after } \\
\text { Treatment }\end{array}$ \\
\hline 1572 & 1.00 & 1.00 & 1.00 & 1.00 \\
1178 & 0.31 & 1.97 & 0.27 & 1.76 \\
1091 & 3.62 & 2.52 & 3.71 & 2.89 \\
1075 & 1.32 & 0.79 & 0.99 & 0.16 \\
1044 & - & 2.46 & - & 2.40 \\
807 & 9.92 & 9.27 & 11.07 & 9.57 \\
\hline
\end{tabular}

From Table 2, it can also be found that there is a big difference between the relative absorbance of pure PPS and PPSBM 1 composites before oxidation treatment. This phenomenon can be explained by the fact that pure PPS resin and PPSBM 1 composites are both blended in a twin-screw extruder for $10 \mathrm{~min}$, and hot pressed by a table-type test press machine. Thus, the oxidation of PPS cannot be avoided in the process of melt blending or injection molding. It needs to be pointed out that adding Bz-MMT can delay the oxidation and cross-linking of PPS in the melting process. The relative absorbance of the $\mathrm{C}-\mathrm{S}$ bond and the $\rho$-disubstituted benzene ring is clearly higher than that of pure 
PPS before treatment. In addition, the relative absorbance of $-\mathrm{SO}-$ and $-\mathrm{SO}_{2}-$ is lower than that of pure PPS.

It is clear that the relative absorbance of the C-S bond in $\mathrm{PPSBM}_{1}$ composites is still higher than that of pure PPS. Additionally, its amount of decrease is lower than that of pure PPS after oxidation treatment, as seen in Figure 7 and Table 2. The amount of increase of $-\mathrm{SO}_{2}-$ group in $\mathrm{PPSBM}_{1}$ composites is lower than that of pure PPS, but the amount of decrease of -SO- group in $\mathrm{PPSBM}_{1}$ composites is higher than that of pure PPS after oxidation treatment. The relative absorbance of the $-\mathrm{SO}_{2}-$ group, $-\mathrm{SO}-$ group, and aryl ether in $\mathrm{PPSBM}_{1}$ composites are also lower than that of pure PPS after treatment. These phenomena indicate that the addition of Bz-MMT delays oxidation and cross-linking during the oxidation treatment. There are two possible reasons for this. Firstly, the Bz-MMT nanolayers can form the exfoliated structure or intercalated structure in the PPS matrix. Thus, the nanolayers can limit the diffusion of $\mathrm{O}_{2}$ and acid in the PPS matrix due to mass transport barrier effect. The nanolayers can also restrict the transfer of oxidative degradation products. Secondly, the Bz-MMT nanolayers can promote the crystallization and perfect the crystal structure [22], which hinders the entrance of $\mathrm{O}_{2}$ and acid into PPS crystals. Therefore, the addition of Bz-MMT improves the oxidation resistance of PPS resin.

\subsubsection{Surface Elements Analysis}

To gain a better understanding of the antioxidative mechanism of Bz-MMT on PPS, the element content and the valence state of PPS and $\mathrm{PPSBM}_{1}$ composites are also measured by an XPS. The XPS spectra of PPS and PPSBM 1 composites after normalized processing are shown in Figure 8. It can be found that PPS and PPSBM 1 composites mainly contain the elements oxygen $(\mathrm{O})$, carbon $(\mathrm{C})$, and sulfur (S) from Figure 8 [30]. After the oxidation treatment, the relative intensity of the $\mathrm{O}$ in pure PPS and PPSBM 1 composites significantly increases, but the amount of increase in pure PPS is much higher than that in PPSBM $_{1}$ composites. The relative intensity ratio of $\mathrm{O}$ and $\mathrm{C}$ in pure PPS resin is 0.27 before oxidation treatment. After the treatment, it reaches 0.54 for pure PPS, and only 0.42 for PPSBM 1 composites. This confirms that $\mathrm{S}$ and $\mathrm{C}$ in PPS combine with a large amount of oxygen during the oxidation treatment, while the addition of Bz-MMT can limit this combination of oxygen to improve the oxidation resistance of PPS.

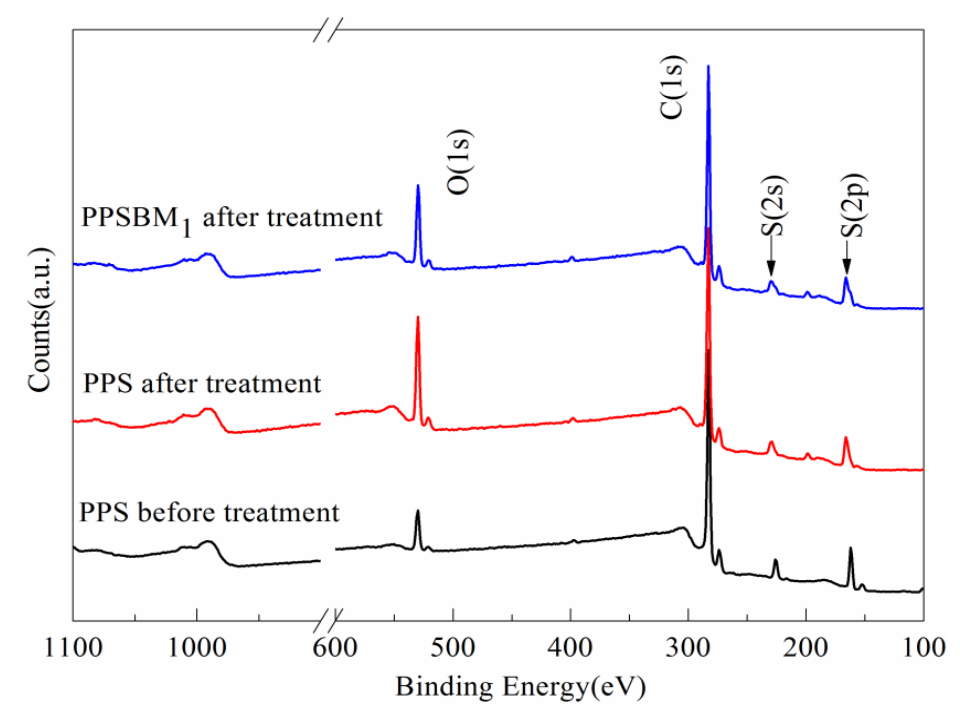

Figure 8. XPS spectra of PPS and PPSBM $_{1}$ composites after treatment.

To further research the valence state changes of the $S$ element, a high-resolution scan of $S_{2 p}$ is also performed. Figure 9 shows the fitting curves of the $S_{2 p}$ XPS spectra of PPS and PPSBM 1 composites. The relative contents of different functional groups of $S$ are also listed in Table 3. From Figure $9 a$, it is 
evident that the $S_{2 p}$ peak of pure PPS before the treatment can be deconvoluted into two major peaks at $163.7 \mathrm{eV}$ and $164.9 \mathrm{eV}$. These are attributed to the C-S bond and -SO- group, respectively [30-32]. It can also be observed that the element $\mathrm{S}$ in PPS is mainly found in the $\mathrm{C}-\mathrm{S}$ bond from Table 3 . Moreover, a proportion of the element $\mathrm{S}(32.6 \%)$ exists in the form of $-\mathrm{SO}-$, because the element $\mathrm{S}$ can be easily oxidized during the process of storage and melting manufacture.
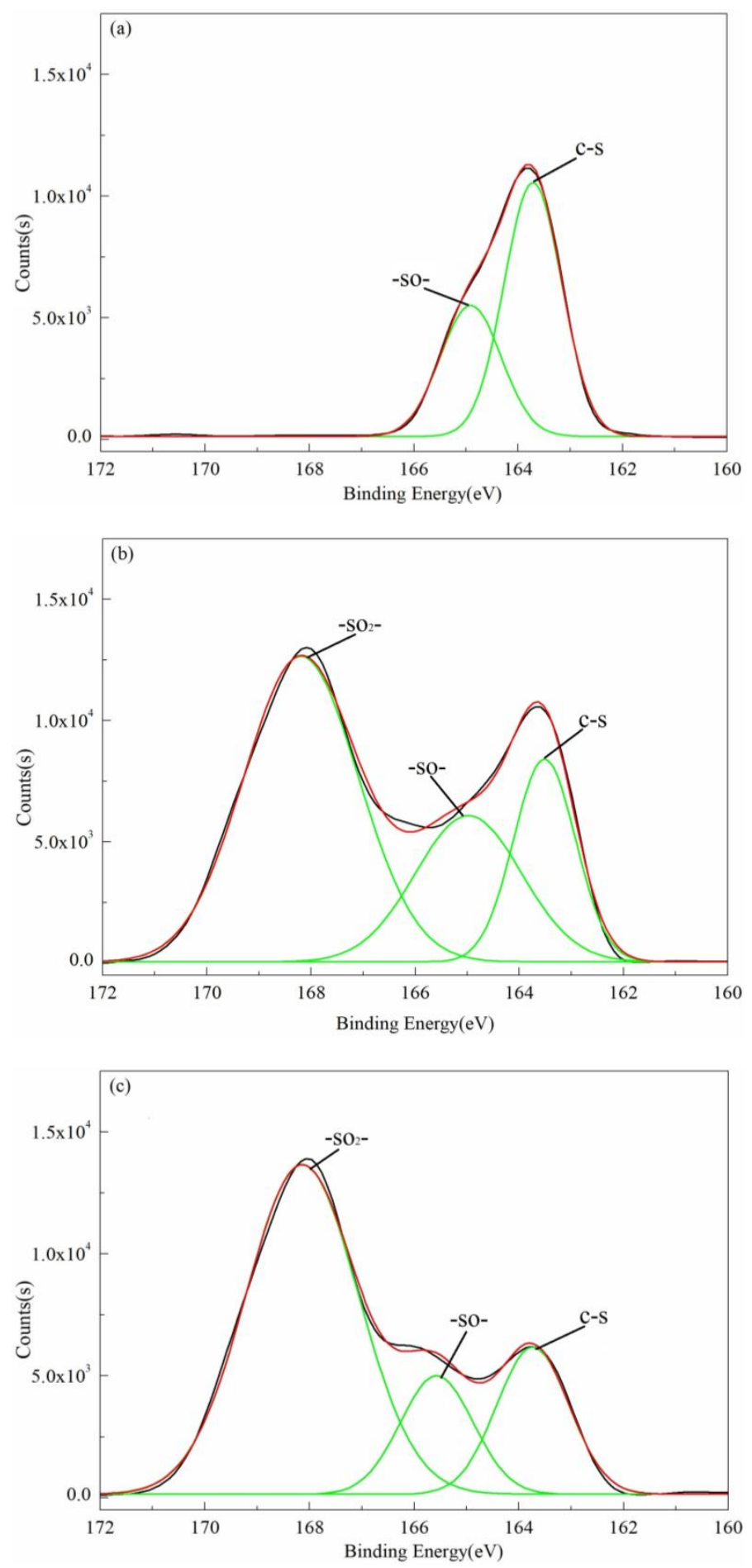

Figure 9. XPS spectra of $S_{2 p}$ in the pure PPS and PPSBM 1 composites: (a) pure PPS before treatment; (b) pure PPS after treatment; (c) $\mathrm{PPSBM}_{1}$ composites after treatment. 
Table 3. Comparison of different functional group in $\mathrm{S}_{2 \mathrm{p}}$ for PPS and PPSBM 1 composites.

\begin{tabular}{cccc}
\hline \multirow{2}{*}{ Samples } & \multicolumn{3}{c}{ Relative Contents (\%) } \\
\cline { 2 - 4 } & $\mathbf{C}-\mathbf{S}$ & $\mathbf{- S O}-$ & $\mathbf{S O}_{\mathbf{2}}-$ \\
\hline PPS before treatment & 67.4 & 32.6 & - \\
PPS after treatment & 14.1 & 29.6 & 56.3 \\
PPSBM $_{1}$ after treatment & 18.8 & 15.6 & 65.6 \\
\hline
\end{tabular}

The $S_{2 p}$ peak of pure PPS after the treatment can be deconvoluted into three peaks at $163.7 \mathrm{eV}$, $164.9 \mathrm{eV}$, and $168.2 \mathrm{eV}$. These are attributed to the $\mathrm{C}-\mathrm{S}$ bond, $-\mathrm{SO}-$ group, and $-\mathrm{SO}_{2}-$ group, respectively [30-32], as observed from Figure 7b. It is clear that the proportion of the C-S bond significantly decreases, while the proportion of the $-\mathrm{SO}_{2}-$ group greatly increases after oxidation treatment. The relative content of the C-S bond decreases from $67.4 \%$ to $14.1 \%$, and that of $-\mathrm{SO}_{2}-$ group can reach $56.3 \%$. This confirms that significant oxidation has taken place in pure PPS resin. For PPSBM 1 composites after the oxidation treatment, the $S_{2 p}$ peak can also be deconvoluted into three peaks corresponding to the $\mathrm{C}-\mathrm{S}$ bond, $-\mathrm{SO}-$ group, and $-\mathrm{SO}_{2}-$ group, respectively. From Table 3, it can also be found that the content of various functional groups is similar to that of pure PPS after the oxidation treatment. However, the relative content of the C-S bond is higher than that of pure PPS, which indicates that the addition of Bz-MMT can prevent the oxidation cleavage of the $\mathrm{C}-\mathrm{S}$ bond in PPS molecular chains.

It is interesting to note that pure PPS has a higher relative content of the -SO-group than $\mathrm{PPSBM}_{1}$ composites after the oxidation treatment. The relative content ratio of the $-\mathrm{SO}-$ group and $-\mathrm{SO}_{2}-$ group is 1:1.9 for pure PPS, while that of $\mathrm{PPSBM}_{1}$ composites can reach 1:4.3. This suggests that the content of the $-\mathrm{SO}_{2}-$ group is richer in $\mathrm{PPSBM}_{1}$ composites after the oxidation treatment. This phenomenon is also consistent with the above ATR-FTIR analysis. Therefore, the addition of Bz-MMT can promote the transfer of the element $\mathrm{S}$ from the $\mathrm{C}-\mathrm{S}$ bond to the $-\mathrm{SO}_{2}$ - group in PPS macromolecular chains, which have a structure similar to polyarylene sulfide sulfone (PASS). The $\mathrm{S}$ in the $-\mathrm{SO}_{2}$ - group reaches the stable valence state and can remain stable under the condition of oxidation. Therefore, the surface of PPS can form a proactive layer with a PASS-like structure due to the addition of Bz-MMT, and this improves oxidation resistance.

\section{Conclusions}

The addition of Bz-MMT can significantly improve the tensile strength of PPS. However, adding a high content of Bz-MMT can also reduce the tensile properties of PPS due to the agglomeration and degradation of Bz-MMT. The thermal stability of PPS is also remarkably improved by the mass transport barrier effect of Bz-MMT nanolayers. However, excessive Bz-MMT also reduces the thermal stability of PPS because of the degradation of the organic modifier. The oxidation resistance analyses confirm that the addition of Bz-MMT markedly decreases the tensile strength loss ratio of PPS after the oxidation treatment. Moreover, adding Bz-MMT can also delay the oxidation cleavage of the $\mathrm{C}-\mathrm{S}$ bond and reduce the generation of $-\mathrm{SO}-$ groups, $-\mathrm{SO}_{2}-$ groups, and aryl ethers. It also restricts the joining together of $\mathrm{S}$ in PPS macromolecules and $\mathrm{O}$ from the external environment. The addition of Bz-MMT promotes the transfer of $\mathrm{S}$ from the $\mathrm{C}-\mathrm{S}$ bond to the $-\mathrm{SO}_{2}-$ group in PPS macromolecular chains. Overall, the antioxidant mechanism of Bz-MMT nanolayers on PPS resin has two explanations. Firstly, the barrier effect of Bz-MMT nanolayers can limit the diffusion and transfer of heat, oxidizing substances, and oxidation products in the PPS matrix in order to retard the oxidation rate. Secondly, adding Bz-MMT can promote the formation of $-\mathrm{SO}_{2}-$ group in the PPS macromolecule chains, which can form a protective layer with a PASS-like structure on the surface of PPS to improve oxidation resistance. 
Acknowledgments: Financial support from Anhui Province University Natural Science Research (No. KJ2017ZD13), Anhui Province International Science and Technology Cooperation Program (1704e1002213) and Scientific Research Fund of Talent Introduction of Anhui Polytechnic University (No. 2017YQQ013).

Author Contributions: Jian Xing conceived and designed the experiments, analyzed the data and wrote the manuscript; Zhenzhen $\mathrm{Xu}$ performed the experiments; Bingyao Deng contributed reagents/materials /analysis tools.

Conflicts of Interest: The authors declare no conflict of interest.

\section{References}

1. Deng, S.L.; Cao, L.; Lin, Z.D.; Qiu, W.P.; Liang, K.Y.; Li, W. Nanidiamond as an efficient nucleating agent for polyphenylene sulfide. Thermochim. Acta 2014, 584, 51-57. [CrossRef]

2. Yang, Y.Q.; Duan, H.J.; Zhang, S.Y.; Niu, P.F.; Zhang, G.; Long, S.R.; Wang, X.J.; Yang, J. Morphology control of nanofillers in poly(phenylene sulfide): A novel method to realize the exfoliation of nanoclay by $\mathrm{SiO}_{2}$ via melt shear flow. Compos. Sci. Technol. 2015, 75, 1685-1693. [CrossRef]

3. Kim, M.; Lee, J.; Roh, H.Y.; Kim, D.; Byeon, J.; Park, J. Effect of covalent functionalization of MWCNTs on the thermal properties and non-isothermal crystallization behaviors of PPS composites. Polymers 2017, 9, 460. [CrossRef]

4. Zhang, X.Z.; Zhang, K.; Zhou, Z.; Chen, L.; Chen, Y. Preparation of radiation-resistant high-performance polyphenylene sulfide fibers with improved processing. Procedia Eng. 2012, 27, 1354-1358. [CrossRef]

5. Liu, Q.; Luo, W.; Chen, Y.; Zou, H.; Liang, M. Enhanced mechanical and thermal properties of CTAB-functionalized graphene oxide-polyphenylene sulfide composites. High Perform. Polym. 2016, 29, 889-898. [CrossRef]

6. Li, C.Y.; Li, Z.H.; Zhang, M.L.; Cheng, B.W. SiC-fixed organophilic montmorillonite hybrids for poly(phenylene sulfide) composites with enhanced oxidation resistance. RSC Adv. 2017, 7, 46678-46689. [CrossRef]

7. Tanthapanichakoon, W.; Furuuchi, M.; Nitta, K.-H.; Hata, M.; Endoh, S. Degradation of semi-crystalline PPS bag-filter materials by $\mathrm{NO}$ and $\mathrm{O}_{2}$ at high temperature. Polym. Degrad. Stab. 2006, 91, 1637-1644. [CrossRef]

8. Wan, J.X.; Qin, Y.F.; Li, S.B.; Wang, X.H. Studies on Preparation and Characterization of Anti-oxidizing polyphenylene sulfide. Adv. Mater. Res. 2011, 332-334, 1045-1048. [CrossRef]

9. Sugama, T. Polyphenylene sulfide/montomorillonite clay nanocomposite coatings: Their efficacy in protecting steel against corrosion. Mater. Lett. 2006, 60, 2700-2706. [CrossRef]

10. Sugama, T. Antioxidants for retarding hydrothermal oxidation of polyphenylene sulfide coating in geothermal environments. Mater. Lett. 2000, 43, 4282-4290. [CrossRef]

11. Sheng, X.Q.; Zhang, R.P.; Niu, M.; Yang, H.; Dai, J.M. Preparation of $\mathrm{SiO}_{2} / \mathrm{PPS}$ fiber and study of its heat-resistant properties. Adv. Mater. Res. 2011, 287-290, 2590-2597. [CrossRef]

12. Liu, T.; Chen, Y.; Yan, B. Study on photo stability of blending modified polyphenylene sulfide fiber. China Syn. Fiber Ind. 2008, 32, 8-11.

13. Sugama, T.; Gawlik, K. Self-repairing poly (phenylene sulfide) coatings in hydrothermal environments at $200{ }^{\circ}$ C. Mater. Lett. 2003, 57, 4282-4290. [CrossRef]

14. Oliveira, M.C.L.; Sayeg, I.J.; Ett, G.; Antunes, R.A. Corrosion behavior of polyphenylene sulfide-carbon black-graphite composites for bipolar plates of polymer electrolyte membrane fuel cells. Int. J. Hydrog. Energy 2014, 39, 16405-16418. [CrossRef]

15. Shi, L.T.; Hu, J.; Lin, X.D.; Fang, L.; Wu, F. A robust superhydrophobic PPS-PTFE $/ \mathrm{SiO}_{2}$ composite coating on AZ31 Mg alloy with excellent wear and corrosion resistance properties. J. Alloy. Compd. 2017, 721, 157-163. [CrossRef]

16. Yu, Q.; Deng, B.Y.; Liu, Q.S.; Lu, Y.Q.; Xing, J. Study on PPS non-woven filter material impregnated by nano $\mathrm{SiO}_{2}$ /PTFE emulsion to improve its performance. J. Tex. Res. 2013, 34, 77-81.

17. Achaby, M.E.; Ennajih, H.; Arrakhiz, F.Z.; Kadib, A.E.; Bouhfid, R. Modification of montmorillonite by novel geminal benzimidazolium surfactant and its use for the preparation of polymer organoclay nanocomposite. Compos. Part B Eng. 2013, 51, 210-317. [CrossRef] 
18. Costache, M.C.; Heidecker, M.J.; Manias, E.; Camino, G.; Frache, A. The influence of carbon nanotubes, organically modified montmorillonites and layered double hydroxides on the thermal degradation and fire retardancy of polyethylene, ethylene-vinylacetate copolymer and polystyrene. Polymer 2007, 48, 6532-6545. [CrossRef]

19. Martino, L.; Guigo, N.; Berkei, J.G.; Sbirrazzuoli, N. Influence of organically modified montmorillonite and sepiolite clays on the physical properties of bio-based poly(ethylene 2,5-furandicarboxylate). Compos. Part $B$ Eng. 2017, 110, 96-105. [CrossRef]

20. Shah, K.J.; Shukla, A.D.; Shah, D.O.; Imae, T. Effect of organic modifiers on dispersion of organoclay in polymer composites to improve mechanical properties. Polymer 2016, 97, 525-532. [CrossRef]

21. Zou, H.; Xu, W.; Zhang, Q.; Fu, Q. Effect of Alkylammonium salt on the dispersion and properties of poly(p-phenylene sulfide)/clay nanocomposites via melt intercalation. J. Appl. Polym. Sci. 2006, 99, 1724-1731. [CrossRef]

22. Xing, J.; Deng, B.Y.; Liu, Q.S. Effect of benzimidazolium salt on dispersion and properties of polyphenylene sulfide/organic clay nanocomposites via melt intercalation. Fiber Polym. 2015, 16, 1220-1229. [CrossRef]

23. Winyu, T.; Hata, M.; Nitta, K.H.; Furuuchi, M.; Otani, Y. Mechanical degradation of fliter polymer materials: Polyphenylene sulfide. Polym. Degrad. Stab. 2006, 91, 2614-2621.

24. Usuki, A.; Hasegawa, N.; Kato, M.; Kobayasgi, S. Polymer-clay nanocomposies, Inorganic Polymeric Nanocomposites and Membranes. Adv. Polym. Sci. 2005, 179, 135-195.

25. Leswzynska, A.; Njugumna, J.; Pielichowski, K.; Banerjee, J.R. Polymer/montmorillonite nanocomposites with improved thermal properties. Part II. Thermal stability of montmorillonite nanocomposites based on different polymeric matrixes. Thermochim. Acta 2007, 454, 1-22. [CrossRef]

26. Morgan, A.B. Flame retarded polymer layered silicate nanocomposites: a review of conmmerical and open literature systems. Polym. Adv. Technol. 2006, 17, 206-217. [CrossRef]

27. Kiliaris, P.; Papaspyrides, C.D. Polymer/layered silicate (clay) nanocomposites: An overview of flame retardancy. Prog. Polym. Sci. 2010, 35, 902-958. [CrossRef]

28. Gu, J.W.; Xie, C.; Li, H.L.; Dang, J.; Geng, W. Thermal percolation behavior of graphene nanoplatelets/polyphenylene sulfide thermal conductivity composites. Polym. Compos. 2014, 35, 1087-1092. [CrossRef]

29. Gu, J.W.; Meng, X.D.; Tang, Y.S.; Li, Y.; Zhuang, Q. Hexagonal boron nitride/polymethyl-vinyl siloxane rubber dielectric thermally conductive composites with ideal thermal stabilities. Compos. Part A Appl. Sci. Manuf. 2017, 92, 27-32. [CrossRef]

30. Yang, D.; Velamakanni, A.; Bozoliu, G.; Park, S.; Stoller, M. Chemical analysis of graphene oxide films after heat and chemical treatment by X-ray photoelectrona and micro-raman spectroscopy. Carbon 2009, 47, 145-152. [CrossRef]

31. Wagner, C.D.; Riggs, W.M.; Muilenberg, G.E. Handbook of X-ray Photoelectron Spectroscopy; Perkin Elmer Corp: Waltham, MA, USA, 1979.

32. Lian, D.D.; Dai, J.M.; Zhang, R.P.; Niu, M.; Huang, Y. Enhancing the resistance against oxidation of polyphenylene sulphide fiber via incporation of nano $\mathrm{TiO}_{2}-\mathrm{SiO}_{2}$ and its mechanistic analysis. Polym. Degrad. Stab. 2016, 129, 77-86. [CrossRef]

(C) 2018 by the authors. Licensee MDPI, Basel, Switzerland. This article is an open access article distributed under the terms and conditions of the Creative Commons Attribution (CC BY) license (http://creativecommons.org/licenses/by/4.0/). 